\title{
Fissür çürüklerinin teşhisinde DIAGNOdent ve Cariescan Pro cihazlarının performansının değerlendirilmesi*
}

Nihal Beldüz Kara', Mehmet Cankat Kara²

Selcuk Dent J, 2016; 3: 92-97

öz

Fissür çürüklerinin teşhisinde DIAGNOdent ve Cariescan Pro cihazlarının performansının değerlendirilmesi

Amaç: $B u$ in vivo çalıșmanın amacı, çürük sıklığının fazla olduğu yeni sürmüş daimi molar dişlerin okluzal çürüklerinin belirlenmesinde lazer esaslı floresans (diagnodent), LED esaslı (Cariescan Pro) çürük teşhis cihazları ve görsel muayenenin karşılaştırılmasıdır.

Gereç ve Yöntemler: Pedodonti kliniğimize başvuran 50 hastanın toplam 200 yeni sürmüş daimi molar dişleri önce Ekstrand'ın gözle muayene yöntemi, sonra da DIAGNOdent ve Cariescan Pro cihazları ile muayene edildi.

Bulgular: Gözle Muayene, DIAGNOdent ve Cariescan Pro metotları arasında istatistiksel olarak anlamlı farkllık bulunurken $(p<0.05)$, DIAGNOdent ve Cariescan Pro metotları arasında tespit edilen istatistiksel olarak anlamlı farklılık gözle muayene ile yapılan analiz sonuçlarına göre daha düşük bulunmuştur.

Sonuç: Çalışmadaki limitasyonlar göz önünde bulundurularak, DIAGNOdent ve Cariescan Pro cihazları çürük teşhisi için benzer değerler ortaya çıkarmıştır. DIAGNOdent ve Cariescan Pro klinik kullanım için uygundur.

ANAHTAR KELIMELER

Cariescan Pro, çürük teşhisi, DIAGNOdent

Çocukluk ve ergenlik dönemlerindeki çürüklerin \%7592'si dişlerin okluzal yüzeylerindeki fissürlerde başlamaktadır (Lussi ve ark. 1995). Çürükler fissür ağızlarının altında fark edilmeden ilerleyebilmekte ve kavite oluşumu çürüğün ileri dönemlerinde ortaya çıkabilmektedir. Bu nedenlerden dolayı, fissür çürüklerinin tanısı daha fazla önem kazanmasına rağmen, erken tanının zorluğu ve klinik muayenenin tek başına yeterli olmadığı unutulmamalıdır (Nytun ve ark. 1992, Ricketts ve ark. 1995a, Ricketts ve ark. 1995b, Sawle ve ark. 1988). Tek başına gözle muayenenin özgüllüğünün yüksek olmasına rağmen, erken başlayan çürüklerin belirlenmesi için duyarlılı̆ının düşük olduğu bildirilmiştir (Loesche ve ark. 1979). Çürüklerin sondla
Başvuru Tarihi: 22 Şubat 2016 Yayına Kabul Tarihi: 05 Mayıs 2016

\section{ABSTRACT}

The evaluation of the performance of DIAGNOdent and Cariescan Pro devices for the detection of fissure caries

Background: The aim of this study was to evaluate the in-vio performance of the DIAGNOdent, the Cariescan Pro devices and visual inspection method for occlusal caries detection in new erupted permanent molars.

Methods: 200 new erupted permanent molars from 50 patients were evaluated with Ekstrand's visual inspection technique and DIAGNOdent, Cariescan Pro devices.

Results: There was a statistically significant difference between the visual inspection technique and DIAGNOdent, Cariescan Pro devices $(p<0.05)$. However, the statistically significant differences between the DIAGNOdent and Cariescan Pro devices were lower than the differences from the visual inspection methods.

Conclusion: Taking the limitations of the current study into consideration, it can be concluded that the DIAGNOdent and the Cariescan Pro devices are equally valid for caries detection. The Cariescan Pro and the DIAGNOdent can be used in clinical settings.

\section{KEYWORDS}

Cariescan Pro, caries detection, DIAGNOdent

muayenesi, çürük yapıcı mikroorganizmaların bir yerden bir yere taşınmasına, remineralize olabilen erken çürük lezyonlarında geri dönüşümü olmayan travmatik defektlere neden olabileceğinden dolayı eleştirilmektedir (Ekstrand ve ark. 1987). Radyografik muayene, erken başlayan okluzal çürüklerin teşhisinde radyasyonun sağlığa zararlı etkilerinden dolayı sınırlı olarak kullanılmaktadır (Smith 1987). Ayrıca, radyografik muayenenin de okluzal yüzeylerdeki fissür çürüklerinin belirlenmesindeki hassasiyetinin de düşük olduğunu belirtilmiştir (Wenzel ve ark. 1991).

\footnotetext{
* Bu çalışma Ordu Üniversitesi Bilimsel Araştırma Projeleri Birimi tarafından desteklenmiştir (AR-1225).

1 Ordu Üniversitesi Diş Hekimliği Fakültesi Pedodonti Anabilim Dalı, Ordu

2 Ordu Üniversitesi Diş Hekimliği Fakültesi Periodontoloji Anabilim Dalı, Ordu
} 
Geleneksel çürük teşhis yöntemlerinin dezavantajlarının üstesinden gelmek için, erken çürüklerin belirlenmesinde birçok non-invasive yöntemler geliştirilmiştir. Abrasyon sistem, electronic caries metod (ECM), fiber optik transiluminasyon (FOTI ve DIFOTI), visible light floresans (QLF), lazer floresans (DIAGNOdent), optical coherence tomografi (OCT), ultrasound, dijital radyografi ve lazer floresans bunlardan birkaçıdır (Rodrigues ve ark. 2008a, Rodrigues ve ark. 2008b, Weerhejim ve ark. 1997, Chong ve ark. 2003, Ricketts ve ark. 1998, Huysmans ve ark. 1998, Verdonschot ve ark. 1999). Teknolojinin gelişmesi ile birlikte çürük lezyonunun objektif olarak değerlendirilmesi ve erken teşhiste hekime yardımcı olması amacıyla $655 \mathrm{~nm}$ dalga boyuna sahip ışının dişin okluzal yüzeyine gönderilip bakteri metabolitleri tarafından yayılan floresent ışığın, fiber optikler tarafından yakalanması ile rakamsal değerleri moniterize eden DIAGNOdent sistem geliştirilmiştir (Tam ve McComb 2001). Shi ve ark. (2000), in vitro çalışmalarında, bu sistemin hem mine hem de dentin çürüklerinin teşhisinde radyografiye göre daha üstün olduğunu belirtmişlerdir. DIAGNOdent tanı cihazının klinik açıdan diğer tanı yöntemlerine göre üstünlükleri de belirtilmiştir (Lussi ve ark. 1999). DIAGNOdentten sonra geliştirilmiş olan en yeni çürük teşhis aleti LED esaslı CarieScan Pro cihazıdır. Yine de CarieScan Pro ile yapılmış yeterli sayıda klinik çalışma bulunmamaktadır.

Pedodontinin temelini oluşturan koruyucu hekimlik konusunda çalışmalarımızı sürdürmek ve araştırmalarımızı derinleştirmek amacıyla fissür çürüklerinin erken tanısında son dönemde geliştirilmiş olan CarieScan Pro cihazının kullanımına imkân sağlanması talep edilmektedir. $\mathrm{Bu}$ çalışmanın amacı, daimi molar dişlerdeki okluzal çürüklerin erken dönemde belirlenmesinde CarieScan Pro ve DIAGNOdent çürük teşhis cihazlarının klinik tanı yöntemlerine göre güvenirliliklerinin tespitidir.

\section{GEREC VE YÖNTEM}

\section{Test materyalleri}

Çalışma için, T.C. Ankara Üniversitesi Diş Hekimliği Fakültesi Etik Kurulu'ndan etik kurul onayı alınmıştır (05.03.2012 tarih ve 31/5 sayılı etik onay). Ayrıca, tedavi öncesinde, yapılacak tedaviler hakkında hasta ve ebeveynler bilgilendirilmiş ve tedavi uygulamaları ve radyografik tetkikleri için ebeveynlerden bilgilendirilmiş onam kağıdı alınmıştır. Çalışmaya, Pedodonti A.D.'na başvuran 50 hastanın toplam 200 yeni sürmüş okluzal yüzleri sağlam veya erken çürüğü bulunan 1. daimi molar dişleri dahil edilmiştir. Okluzal restorasyonlu ve fissür örtücü uygulanmış dişler, hipoplastik pitler ve çürük kaynaklı açık okluzal kavitasyonlu dişler çalışmadan çıkarılmıştır. Seçilen dişlerde plak veya diştaşı varsa ultrasonik skaler uçlar ile uzaklaştırıldıktan sonra görsel muayene, DIAGNOdent ve CarieScan Pro cihazı ile muayene edilmiştir. Seçilen dişler önce hava ile kurutulduktan sonra Ekstrand'ın gözle muayene skorlama sistemi (V0: hava ile kurutmadan sonra mine translusensliğinden hiç veya hafif değişiklik, V1: hava ile kurutmadan sonra belirgin bir şekilde renklenme veya opasite, V3: dentinin altında gri renklenme ve/veya renklenmiş mine veya opakta lokalize olmuş mine kırığı, V4: dentine uzanan renklenmiş mine veya opakta kavitasyon) kullanılarak çürüğün durumu teşhis edilmiştir.

Gözle muayeneden sonra DIAGNOdent ile dişler ölçülmüştür. DIAGNOdent çürük teşhis cihazı özel seramik parça kullanılarak kalibre edildikten sonra lazer floresans muayenesi yapılmıştır. Her diş için standart değer dişin sağlam bukkal yüzeyi ölçülerek kalibre edilmiştir. Bu değer daha sonraki okumalardan elektronik olarak çıkarılmıştır. Dişler üretici firma önerileri doğrultusunda değerlendirilmiştir (Tablo 1). Lazer uç, kuru yüzeydeki hedef bölgeye yerleştirilerek, çürüğün en gelişmiş bölgesindeki değerleri toplamak için lazer ucun uzun aksı boyunca dişin etrafında döndürülmüştür. Böylelikle ekrandaki en yüksek değerler kaydedilerek ve üç okumanın ortalaması alınmıştır.

\section{Tablo 1.}

DIAGNOdent, Cariescan Pro ve gözle muayene ölçümleri için çalışmada kullanılan muayene kriterleri

\begin{tabular}{|c|c|c|c|}
\hline SKORLAR & DIAGNODENT & CARIESCAN PRO & GÖRSEL MUAYENE \\
\hline Skor 0 & $0-10$ & 0 / yeşil ışık & Mine normal yapıda \\
\hline Skor 1 & 44136 & 1-50 / yeşil ışık & $\begin{array}{c}\text { Minede Madde Kaybı } \\
\text { Olmaksızın } \\
\text { Renklenme veya } \\
\text { Opaklaşma }\end{array}$ \\
\hline Skor 2 & $21-30$ & 51-90 / sarı ışık & $\begin{array}{c}\text { Mine Fissür } \\
\text { Çevresindeki } \\
\text { Dentinde Renklenme } \\
\text { Yumuşak Yoğunlukta } \\
\text { Opaklık veya } \\
\text { Renklenme, } \\
\text { Mikrokavitasyon }\end{array}$ \\
\hline Skor 3 & $31+$ & 91-100 / kırmızı ışık & $\begin{array}{l}\text { Madde Kaybıyla } \\
\text { Birlikte Opak ve } \\
\text { Yumuşak Fissür }\end{array}$ \\
\hline
\end{tabular}

DIAGNOdent ile ölçümden sonra aynı dişler CarieScan Pro cihazı ile ölçülmüştür. CarieScan PRO, izole edildikten ve kurutulduktan sonra diş yüzeyine uygulanabilinen bir el çürük tespit aygıtıdır. CarieScan Pro özel seramik parça kullanılarak kalibre edilmiştir. Oklüzal yüzey değerlendirmesi için hedef fissüre probun ucu direkt olarak ve dişin uzun aksına paralel olacak şekilde yerleştirilmiştir. Cihazın ucu 
yaklaşık 3-5 saniye diş yüzeyinde kaldıktan sonra 0 ile 100 arasında değişen bir skor belirlenmiştir. 0-50 arasında değişen skor düşük olasılık; 51 ile 90 orta düzeyde olasilık ve 91-100 yüksek olasılıkta çürüğü işaret etmektedir. Kırmızı, Sarı ve Yeşil LED piramitler sayısal skora karşııı olarak cihaz üzerinde aydınlatılmıştır. Buna göre, yeşil piramit $0-50$, sarı $51-90$ ve 91-100 kırmızı rengi işaret etmektedir.

Çürük veya diş yüzeyindeki dekalsifikasyon varlığına göre alet renkli ışıkla birlikte 0 ile 100 arasında skor verecektir. Tüm ölçümlerden sonra dişin okluzal yüzeyinde gözle muayenede V1, V3, V4 ve Diagnodent ile ölçümde 20 ve 20'nin üzerinde değer ve CarieScan Pro cihazı ile orta ve yüksek seviyede skor gösterdiği zaman hastalar pit ve fissürlerin açılmasından sonra uygun konservatif ve restoratif tedaviyi yapmak için ikinci seansa çağrılmıştır. Fissürler ince uçlu karbit frezle açıldıktan sonra HeinrichWeltzien ve ark'ndan adapte edilen kodlar (BO: çürük yok, B1: minede sonlanan çürük varlığı B2: dentine uzanan çürük varlığı) kullanılarak çürük değerlendirilmiştir. Çürük dikkatli bir şekilde uzaklaştırılıktan sonra kavitenin varlığı veya derinliğine bağlı olarak fissür örtücü, kompozit veya koruyucu rezin restorasyon ile restore edilmiştir.

Çalışma sürecinde tüm değerlendirmeler ve tedaviler aynı hekim (NBK) tarafından yapılmıştır. Bütün analizler SPSS istatistik programı 15.0 kullanılarak gerçekleştirildi. Önem seviyesi $p<0.05$ idi. Spearman'ın korelasyon katsayısı testi her bir teşhis yönteminin bulgularının birbirleriyle ilişkilendirilmesi için kullanıldı.

\section{BULGULAR}

Hastaların demografik ve klinik dental özellikleri Tablo 2'de gösterildi. Gözle Muayene, DIAGNOdent ve Cariescan Pro okumasına göre sayı açısından dişlerin dağılımı Tablo 3'de gösterildi. Tablo 4, Tablo 5 ve Tablo 6'da çürük skorlarının kros tablo dağılımı sonuçları yer aldı. Spearman'ın korelasyon katsayısı testi sonucuna göre, Gözle Muayene, DIAGNOdent ve Cariescan Pro metotları arasında istatistiksel olarak anlamlı farklılık bulunurken $(p<0.05)$, DIAGNOdent ve Cariescan Pro metotları arasında tespit edilen istatistiksel olarak anlamlı farklılık gözle muayene ile yapılan analiz sonuçlarına göre daha düşüktü (Tablo 7).

Tablo 2.

\section{Hastaların demografik ve klinik dental özellikleri}

\begin{tabular}{|ccc|}
\hline Kiz & Erkek \\
\hline Cinsiyet (n) & 28 & 22 \\
\hline Yaş & $8,18 \pm 1,06$ & $7,77 \pm 1.11$ \\
\hline $\begin{array}{c}\text { Diş Fırçalama } \\
\text { (n/gün) }\end{array}$ & $1,00 \pm 0.67$ & $0,73 \pm 0,70$ \\
\hline $\begin{array}{c}\text { Örnek diş } \\
\text { sayısı } \\
\text { (1. daimi } \\
\text { molar) }\end{array}$ & 112 & 88 \\
\hline
\end{tabular}

Tablo 3.

Dişlerin, muayene metotları ve çürük skorlarına göre dağılımı

\begin{tabular}{|ccccc|}
\hline & \multicolumn{4}{c}{ Çürük Skorları } \\
& $\mathbf{0}$ & $\mathbf{1}$ & $\mathbf{2}$ & $\mathbf{3}$ \\
\hline Gözle muayene & 51 & 96 & 40 & 13 \\
\hline DIAGNOdent & 22 & 47 & 89 & 42 \\
\hline Cariescan Pro & 18 & 57 & 88 & 37 \\
\hline
\end{tabular}

Tablo 4.

Gözle muayene ve Cariescan Pro çürük skorlarının cross tablo dağılımı

\begin{tabular}{|cccccc|}
\hline & \multicolumn{5}{c|}{ Cariescan Pro } \\
Gözle Muayene & $\mathbf{0}$ & $\mathbf{1 - 5 0}$ & $\mathbf{5 1 - 9 0}$ & $\mathbf{9 1 - 1 0 0}$ & $\mathbf{N}$ \\
\hline 0 & 18 & 23 & 9 & 1 & $\mathbf{5 1}$ \\
\hline 1 & 0 & 32 & 47 & 17 & 96 \\
\hline 2 & 0 & 2 & 32 & 6 & 40 \\
\hline 3 & 0 & 0 & 0 & 13 & 13 \\
\hline N & $\mathbf{1 8}$ & $\mathbf{5 7}$ & $\mathbf{8 8}$ & $\mathbf{3 7}$ & $\mathbf{2 0 0}$ \\
\hline
\end{tabular}

Tablo 5.

Gözle muayene ve DIAGNOdent çürük skorlarının kros tablo dağılımı

\begin{tabular}{|cccccc|}
\hline & \multicolumn{5}{c|}{ DIAGNOdent } \\
Gözle Muayene & $\mathbf{0 - 1 0}$ & $\mathbf{4 4 . 1 3 6}$ & $\mathbf{2 1 - 3 0}$ & $\mathbf{3 1 +}$ & $\mathbf{N}$ \\
\hline 0 & 21 & 20 & 9 & 1 & $\mathbf{5 1}$ \\
\hline 1 & 1 & 26 & 50 & 19 & $\mathbf{9 6}$ \\
\hline 2 & 0 & 1 & 30 & 9 & $\mathbf{4 0}$ \\
\hline 3 & 0 & 0 & 0 & 13 & $\mathbf{1 3}$ \\
\hline N & $\mathbf{2 2}$ & $\mathbf{4 7}$ & $\mathbf{8 9}$ & $\mathbf{4 2}$ & $\mathbf{2 0 0}$ \\
\hline
\end{tabular}

Tablo 6.

\section{DIAGNOdent ve Cariescan Pro çürük skorlarının kros tablo dağılımı}

\begin{tabular}{|cccccc|}
\hline & \multicolumn{5}{c|}{ Cariescan Pro } \\
\hline Gözle Muayene & $\mathbf{0}$ & $\mathbf{1 - 5 0}$ & $\mathbf{5 1 - 9 0}$ & $\mathbf{9 1 - 1 0 0}$ & $\mathbf{N}$ \\
\hline $0-10$ & 18 & 4 & 0 & 0 & $\mathbf{2 2}$ \\
\hline $11-20$ & 0 & 43 & 4 & 0 & $\mathbf{4 7}$ \\
\hline $21-30$ & 0 & 10 & 79 & 0 & $\mathbf{8 9}$ \\
\hline $31+$ & 0 & 0 & 5 & 37 & $\mathbf{4 2}$ \\
\hline $\mathbf{N}$ & $\mathbf{1 8}$ & $\mathbf{5 7}$ & $\mathbf{8 8}$ & $\mathbf{3 7}$ & $\mathbf{2 0 0}$ \\
\hline
\end{tabular}


Tablo 7.

Cariescan Pro, DIAGNOdent ve gözle muayene için Spearman'ın korelasyon katsayısı testi sonuçları

\begin{tabular}{|ccc|}
\hline & DIAGNOdent & Cariescan Pro \\
\hline Gözle Muayene & $0,637^{\star}$ & $0,617^{\star}$ \\
\hline DIAGNOdent & 1 & 0.922 \\
\hline
\end{tabular}

\section{TARTIŞMA}

Çalışmadan elde edilen bulgularla Cariescan Pro ile DIAGNOdent çürük teşhisinde etkin aletler olduğu görülmüş ve hipotezimiz desteklenmiştir. Çürük teşhisinde çeşitli metotlar kullanılmaktadır. Gözle muayene ve radyografik muayene bilinen geleneksel muayene yöntemlerindendir (Bader ve ark. 2001). Bu yöntemlerin ayrı veya birlikte kullanımı çürük teşhisinde subjektif sonuçlar ortaya çıkarır (de Paula ve ark. 2011). Çürüğün değerlendirilmesinde objektif metotların kullanımı daha kesin ve net sonuçların elde edilmesine yol açar. DIAGNOdent son zamanlarda kullanımı yaygınlaşan ve objektif veriler sunan çürük teşhis cihazıdır. DIAGNOdent ile yapılan in vitro ve in vivo çalışmalar göstermiştir ki bu cihaz yüksek gözlemci içi ve gözlemci arası uyum ile çürük teşhisinde etkin bir alettir (Rodrigues ve ark. 2009, Lussi ve Hibst 2004). Dental literatür tarandığında Cariescan Pro çürük teşhis cihazı ile ilgili yapıımış araştırma sayısının çok az olduğu görülmüştür (Jablonski ve Christin 2015). Çalışmamıza göre Cariescan Pro DIAGNOdent kadar çürük teşhisinde güvenilir olarak bulunmuştur. Bu çalışmada fissür çürük teşhisinde gözle muayenede düşük değerler elde edilmiştir. Fakat bu bulgu, literatüre zit bir veridir. 22 DIAGNOdent ile gözle muayene arasındaki karşılaştırmalı çalışmalarda DIAGNOdentin gözle muayeneye göre yüksek özgüllüğe sahip olduğu görülmektedir (Reis ve ark. 2006). Bu bulgu çalışmamızın bulgularıyla benzerlik göstermektedir. $\mathrm{Bu}$ çalışmanın sonucuna göre; DIAGNOdent ile Cariescan Pro'nun oklüzal çürük teşhisi için benzer ve olumlu sonuçlar vermesine karşın, birçok açıdan iki çürük teşhis cihazı arasında farklılıklar mevcuttur. DIAGNOdent Cariescan Pro verileri sayısal olarak elde edilirken, Cariescan Pro'nun sayısal verileri daha geniş aralıkta sonuç vermektedir. $\mathrm{Bu}$ durum Cariescan Pro'yu DIAGNOdent'e göre daha objektif kılarken, daha deneyimsiz hekim için Cariescan Pro'nun daha iyi sonuçlar vereceğini akla getirmektedir. Bu in vivo çalışma Cariescan Pro çürük teşhis cihazı için öncül bir çalışmadır. Bu yüzden çalışmamızda bazı limitasyonlar mevcuttur. Öncelikle çalışma invivo bir çalışma olduğu için elde edilen verilerin doğruluğunu test etmek için herhangi bir histolojik kıyaslama yapılamamıştır.

\section{SONUÇ}

Çalışmadaki limitasyonlar göz önünde bulundurularak, DIAGNOdent ve Cariescan Pro çürük teşhis cihazları çürük teşhisi için benzer değerler ortaya çıkmıştır. DIAGNOdent ve Cariescan Pro klinik kullanım için uygundur. Daha fazla örnek sayısı ve farklı yüzeyler göz önüne alınarak Cariescan Pro ile hem in vitro hem de in vivo ortamda farklı çalışmalar ortaya konmalıdır. 


\section{KAYNAKLAR}

Bader JD, Shugars DA, Bonito AJ, 2001. Systematic reviews of selected dental caries diagnostic and management methods. J Dent Educ, 65, 960-968.

Chong MJ, Seow WK, Purdie DM, Cheng E, Wan V, 2003. Visual-tactile examination compared with conventional radiography, digital radiography, and DIAGNOdent in the diagnosis of occlusal occult caries in extracted premolars. Pediatr Dent, 25, 341349.

de Paula AB, Campos JA, Diniz MB, Hebling J, Rodrigues JA, 2011. In situ and in vitro comparison of laser fluorescence with visual inspection in detecting occlusal caries lesions. Lasers Med Sci, 26, 1-5.

Ekstrand K, Qvist V, Thylstrup A, 1987. Light microscope study of the effect of probing in occlusal surfaces. Caries Res, 21(4), 368-374.

Huysmans MCDNJM, Longbottom $\mathrm{C}$, Hintze $\mathrm{H}$, Verdonschot EH, 1998. Surfacespecific electrical occlusal caries diagnosis: reproducibility correlation with histological lesion depth and tooth type dependence. Caries Res, 32, 330-336.

Jablonski-Momeni A and Christin Klein SM, 2015. InVivo Performance of the CarieScan Pro Device for Detection of Occlusal Dentine Lesions. The Open Access Journal of Science and Technology, 3, 1-6.

Loesche WJ, Svanberg ML, Pape HR, 1979. Intraoral transmission of Streptococcus mutans by a dental explorer. J Dent Res, 58(8), 1765-1770.

Lussi A, Hotz P, Stich H, 1995. Fissure caries. Their diagnosis and therapeutic principles. Schweiz Monatsschr Zahnmed, 105(9), 1164-1173.

Lussi A, Imwinkelried S, Pitts N, Longbottom C, Reich E, 1999. Performance and reproducibility of a laser fluorescence system for detection of occlusal caries in vitro. Caries Res, 33(4), 261-266.

Lussi A, Hibst R, Paulus R, 2004. DIAGNOdent: An optical method for caries detection. J Dent Res, 83, 80-83.

Nytun RB, Raadal M, Espelid I, 1992. Diagnosis of dentin involvement in occlusal caries based on visual and radiographic examination of the teeth. Scand $J$ Dent Res, 100(3), 144-148.
Reis A, Mendes FM, Angnes V, Angnes G, Grande $\mathrm{RH}$, Loguercio $A D, 2006$. Performance of methods of occlusal caries detection in permanent teeth under clinical and laboratory conditions. J Dent, 34, 89-96.

Ricketts DN, Kidd EA, Beighton D, 1995a. Operative and microbiological validation of visual, radiographic and electronic diagnosis of occlusal caries in non-cavitated teeth judged to be in need of operative care. Br Dent J, 179(6) 214-220.

Ricketts DN, Kidd EA, Smith BG, Wilson RF, 1995b. Clinical and radiographic diagnosis of occlusal caries: a study in vitro. J Oral Rehabil, 22(1), 15-20.

Ricketts DNJ, Watson TF, Liepins PJ, Kidd EA, 1998. A comparison of two histological validating techniques for occlusal caries. Int Dent J, 26, 8996.

Rodrigues JA, Hug I, Diniz MB, Lussi A, 2008a. Performance of floresans methods, radiographic examination and ICDASII on occlusal surfaces in vitro. Caries Res, 42, 297-304.

Rodrigues JA, de Vita TM, Cordeiro RCL, 2008b. In vitro evaluation of the influence of air abrasion on detection of occlusal caries lesions in primary teeth. Pediatr Dent, 30, 15-18.

Rodrigues JA, Diniz MB, Josgrilberg EB, Cordeiro RC, 2009. In vitro comparison of lazer floresans performance with visual examination for detection of occlusal caries in permanent and primary molars. Lasers Med Sci, 24, 501-506.

Sawle RF, Andlaw RJ, 1988. Has occlusal caries become more difficult to diagnose? A study comparing clinically undetected lesions in molar teeth of 14-16-year old children in 1974 and 1982. Br Dent J, 164(7), 209-211.

Shi XQ, Welander U, Angmar-Mansson B, 2000. Occlusal caries detection with Kavo DIAGNOdent and radiography: an in vitro comparison. Caries Res, 34, 151-158.

Smith NJ, 1987. Risk assessment: the philosophy underlying radiation protection. Int Dent $\mathrm{J}, 37(1)$, 43-51. 
Tam LE and McComb D, 2001. Diagnosis of occlusal caries: Part II. Recent diagnostic technologies. J Can Dent Assoc, 67(8), 459-463.

Verdonschot EH, Angmar-Mansson B,ten Bosch JJ, Deery CH, Huysmans MC, Pitts NB, Waller E, 1999. Developments in caries diagnosis and their relationship to treatment decisions and quality of care. Caries Res, 33, 32-40.

Weerheijm KL, Kidd E, Groen HL, 1997. The effect of fluoridation on the occurrence of hidden caries in clinically sound occlusal surfaces. Caries Res, 31, 30-34.

Wenzel A, Larsen MJ, Fejerskov O, 1991. Detection of occlusal caries without cavitation by visual inspection, film radiographs, xeroradiographs, and digitized radiographs. Caries Res, 25(5), 365-371.

Yazışma Adresi:

Nihal BELDÜZ KARA

Ordu Üniversitesi

Diş Hekimliği Fakültesi Pedodonti AD

Ordu, Türkiye

Tel : + 904522121283

E-mail: nihalpedo@yahoo.com 